\title{
Informações médicas obtidas pelo Google são mais isentas em inglês do que em português.
}

Tiago Zimerman, André Zimerman, Leandro I. Zimerman.

\section{Resumo}

Introdução: Ferramentas de busca online, como o "Google", são utilizadas para pesquisar doenças, embora possuam risco inerente de apresentar resultados de baixa qualidade. Em relação aos de língua portuguesa, países de língua inglesa são usualmente mais desenvolvidos e possuem instituições de maior renome, o que poderia representar diferente perfil de confiabilidade nos sites de busca.

O objetivo desse trabalho é comparar, entre as línguas inglesa e portuguesa, a confiabilidade e a quantidade dos sites listados ao buscar distúrbios cardíacos comuns.

Métodos: Foi utilizado o "Google" para pesquisar, em inglês e em português, as palavras endocardite, estenose aórtica, fibrilação atrial, hipertensão arterial, infarto agudo do miocárdio, insuficiência cardíaca, morte súbita cardíaca, pericardite, síncope e síndrome coronariana aguda. Para avaliação de qualidade, os 10 primeiros resultados obtidos para cada termo foram classificados em duas categorias: isentos (universidades, hospitais, sociedades) e não isentos (pessoais, de clínicas privadas, indústria). O percentual de isentos versus não isentos nos grupos inglês e português foi comparado usando teste de qui-quadrado com correção de Yates, sendo $\mathrm{p}<0,05$ considerado significativo.

Resultados: O número total de resultados obtidos na busca em inglês foi aproximadamente 30 vezes aquele em português (146.231.000 versus 4.933.400), e foi superior para cada um dos dez termos buscados. Entre os 10 primeiros resultados obtidos na 
busca de cada um dos termos, houve maior percentual de isenção naqueles de língua inglesa em relação aos de língua portuguesa (63 versus $36 \% ; \mathrm{p}=0,0002$ ).

Conclusão: Ao utilizar ferramenta de busca online, a pesquisa por termos médicos em português apresenta menor quantidade de resultados e menor grau de confiabilidade em relação ao observado em inglês. 
